\title{
DETEKSI DINI RESIKO JATUH PADA LANSIA DI POSYANDU LANSIA KENTINGAN, KECAMATAN JEBRES, SURAKARTA
}

\author{
Erika Dewi Noorratri'), Ari Septi Mei Leni ${ }^{2)}$, Ipa Sari Kardi' \\ ${ }^{1}$ Fakultas Ilmu Kesehatan Universitas Aisyiyah Surakarta \\ ${ }^{2}$ Fakultas Ilmu Kesehatan Universitas Aisyiyah Surakarta \\ ${ }^{3}$ Fakultas Ilmu Kesehatan Universitas Aisyiyah Surakarta \\ E-mail: erika.dewi2020@gmail.com
}

\begin{abstract}
Background:The falling risk is an event reported by a patient or family who sees an incident, which results in a person suddenly lying, sitting on the floor or lower place with or without loss of consciousness or injury. Falls can occurwhen the body's postural, control system fails to detectshifting and not repositioning the center of gravity toward the body support at the right time. In Indonesia, the elderly who live in communities experience an annual fall or around $30 \%$. The incidence of falls in the elderly living in the community increased from $25 \%$ at the age 70 to $35 \%$ after being over 75 years old. One cause of the fall is a disturbance in the pattern of roads. Therefore it is necessary to practice early detection of the risk of falling in the elderly. Target and output 100\% of extension participants consisting of the elderly can increase their knowledge and understanding of early detection training on the risk of falling on the elderly. Methods of conducting lectures and demonstrations or exercises. The result of the elderly can mention how to detect risk in the elderly and can do exercises to prevent falls. Conclusion elderly know how to detect the risk of early fall in the elderly.
\end{abstract}

Keywords : early detection, fall, elderly

\section{PENDAHULUAN}

Resiko jatuh adalah suatu kejadian yang dilaporkan penderita atau keluarga yang melihat kejadian, yang mengakibatkan seseorang mendadak terbaring, terduduk di lantai atau tempat yang lebih rendah dengan atau tanpa kehilangan kesadaran atau luka (Darmojo, 2004) (dalam Ashar,P. H. 2016). Menurut (Stanley, 2006) (dalam
Ashar, P.H, 2016) resiko jatuh adalah suatu kejadian yang menyebabkan subjek yang sadar menjadi berada di lantai tanpa disengaja. Bukan merupakan jatuh bila kejadian jatuh diakibatkan pukulan keras, kehilangan kesadaran atau kejang. Kejadian jatuh merupakan penyebab spesifik yang berbeda dari mereka yang dalam keadaan sadar mengalami jatuh. Jatuh dapat terjadi ketika sistem kontrol postural tubuh gagal 
mendeteksi pergeseran serta tidak mereposisi pusat gravitasi terhadap penopang tubuh pada waktu yang tepat. Di Indonesia, lansia yang tinggal di komunitas mengalami jatuh setiap tahunnya sekitar 30\%. Insiden jatuh pada lansia yang tinggal di komunitas meningkat dari $25 \%$ usia 70 tahun menjadi 35\% setelah berusia lebih dari 75 tahun. Salah satu penyebab jatuh yaitu gangguan pola jalan (Stanley dan Beare, 2007) (dalam Condrowati, 2015). Zheng et al., 2009 (dalam Ashar,P. H. 2016) mengatakan lanjut usia yang mengalami jatuh dan tidak terdeteksi dalam jangka waktu yang lama akan membawa banyak konsekuensi yang mungkin terjadi. Pendeteksian dini jatuhnya lanjut usia akan membantu untuk meminimalkan kemungkinan ini dengan mengurangi waktu antara terjadinya peristiwa dan kedatangan pertolongan dari medis. Pertumbuhan manusia lanjut usia di dunia berkembang sangat pesat. Kebanyakan masalah yang sering dialami oleh manusia lanjut usia adalah meningkatnya resiko untuk terjatuh. Hal ini dikarenakan fungsi organ tubuh mereka yang telah menurun. Selain organ tubuh mereka yang menurun juga disebabkan oleh penurunan pada fungsi biologis, fisiologis, psikososial dan spiritual. Menurut Viet \& Choi (2011),(dalam Ashar,P. H. 2016). insiden jatuh dapat mengakibatkan dampak fisik (paling sering terjadi cedera di kepala) dan efek fisiologis (ketakutan akan jatuh). Jika penanganan darurat datang terlambat, maka cedera jatuh dapat mengakibatkan cacat, kelumpuhan, bahkan kematian. Penuaan merupakan proses normal perubahan yang berhubungan dengan waktu, sudah dimulai sejak lahir dan berlanjut sepanjang hidup. Usia tua adalah fase akhir dari rentang kehidupan (Fatimah, 2010). Proses penuaan akan berdampak pada berbagai aspek kehidupan, baik sosial, ekonomi maupun kesehatan. Ditinjau dari aspek kesehatan, dengan semakin bertambah usia maka lansia lebih rentan terhadap berbagai keluhan fisik, baik karena faktor alamiah maupun faktor penyakit ( Infodatin, 2014).

Menurut WHO tahun 2015 (dalam Fristantia, D.A. et al. 2017) menyatakan bahwa populasi lansia di dunia antara tahun 2015 dan 2050 diperkirakan meningkat dua kali lipat dari $12 \%$ menjadi $22 \%$ atau sekitar 900 juta menjadi 2 milyar pada usia diatas 60 tahun. Di Indonesia prevalensi cidera jatuh pada penduduk diatas usia 55 tahun mencapai 49,4\%, umur diatas 65 tahun keatas 67,1\% (Kemenkes, RI, 2013) (dalam Fristantia, D.A. et al. 2017) Insidensi jatuh setiap tahunnya di antara lansia yang tinggal di komunitas meningkat dari 25\% pada usia 70 tahun menjadi 35\% setelah berusia lebih dari 75 tahun (Stanley \& Beare, 
2012) (dalam Fristantia, D.A. et al. 2017). Menurut Darmojo dan Martono, 2009 (dalam Fristantia, D.A. et al. 2017) Kejadian jatuh dilaporkan terjadi pada sekitar 30\% lansia berusia 65 tahun ke atas yang tinggal di rumah (komunitas), separuh dari angka tersebut mengalami jatuh berulang. Lansia yang tinggal dirumah mengalami jatuh sekitar 50\% dan memerlukan perawatan di rumah sakit sekitar 10-25\%. Yokoya et al. 2006 (dalam Azizah, F.D, 2017) mengatakan bahwa resiko jatuh sangat rendah pada lanjut usia dengan kemampuan aktivitas yang tinggi, sehingga disarankan untuk meningkatkan frekuensi aktivitas di luar rumah untuk mengurangi resiko jatuh. Tujuan dari pengabdian ini yaitu untuk meningkatkan pengetahuan dan melatih cara untuk mendeteksi dini resiko jatuh pada lansia.

\section{TARGET DAN LUARAN}

Target luaran yang diharapkan dari pengabdian ini adalah:

1. $100 \%$ dari peserta penyuluhan yang terdiri dari lansia dapat meningkatkan pengetahuan dan memahami tentang pelatihan deteksi dini resiko jatuh pada lansia.

2. Terwujudnya program penyuluhan dan pelatihan deteksi dini resiko jatuh yang berkesinambungan terutama untuk pe- ningkatan pengetahuan khususnya tentang deteksi dini resiko jatuh pada lansia.

3. Keterbatasan sumber dana dan sumber daya manusia dalam kegiatan pelatihan deteksi dini resiko jatuh pada lansia.

4. Jurnal yang diterbitkan di Gemassika Universitas 'Aisyiyah Surakarta.

\section{METODE PELAKSANAAN}

Metode yang digunakan adalah ceramah dan demonstrasi bagaimana mendeteksi dini resiko terjadinya jatuh pada lansia. Tujuan akhir dari kegiatan ini adalah dalam rangka meningkatkan kesadaran dan pengetahuan dari pihak terkait. Metode yang digunakan agar tercapai tujuan dari usulan pengabdian masyarakat ini adalah:

1. Pemberian materi yang akan disampaikan sehingga memudahkan peserta untuk mempelajari dan mengikuti pesan yang disampaikan

2. Ceramah sebagai metode komunikasi searah dan diskusi atau tanya jawab sebagai metode komonikasi dua arah.

3. Pelatihan deteksi dini resiko jatuh pada lansia sebagai sarana untuk lebih mengetahui supaya tidak terjadi jatuh pada lansia. 


\section{HASIL DAN PEMBAHASAN}

Kegiatan dilaksanakan pada hari Senin tanggal 15 Juni 2020 bertempat di Posyandu Lansia Melati Arum Kentingan, Jebres, Surakarta yang dihadiri ibu-ibu pengurus posyandu lansia sebanyak 12 orang. Kegiatan ini adalah melakukan penyuluhan dan pelatihan kesehatan atau peningkatan pengetahuan ibu-ibu pengurus posyandu lansia tentang Deteksi dini resiko jatuh pada lansia. Sebelum acara penyuluhan dimulai diisi pembukaan dan sambutan oleh perwakilan dari team pengabdian Universitas Aisyiyah Surakarta dan Ketua Posyandu Lansia Melati Arum Kentingan, Jebres, Surakarta, kemudian dilanjutkan dengan presentasi tentang Deteksi dini resiko jatuh pada lansia kemudian dilanjutkan diskusi. Setelah itu dilanjutkan dengan Pelatihan Deteksi dini resiko jatuh pada lansia oleh team pengabdian dari Universitas Aisyiyah Surakarta.

Berikut hasil antara sebelum dan sesudah dilakukan penyuluhan kesehatan tentang deteksi dini resiko jatuh pada lansia dan hasil pelatihan deteksi dini resiko jatuh pada lansia di Posyandu Melati Arum dan Posyandu Marsudi Waras :

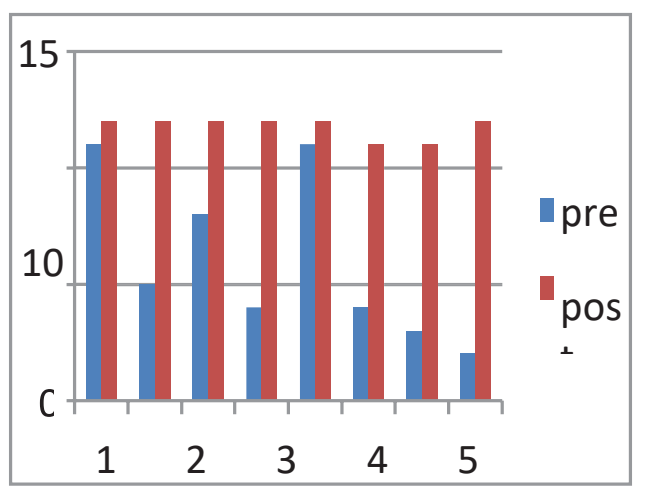

Diagram 1.1 Pengetahuan tentang Deteksi Resiko Jatuh di Posyandu Melati Arum

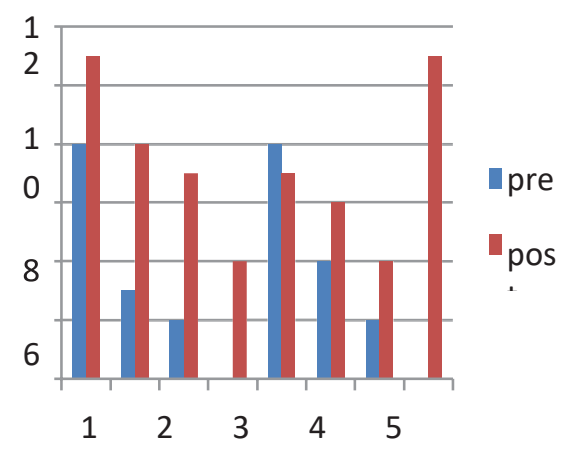

Diagram 1.2 Pengetahuan tentang Deteksi Resiko Jatuh di Posyandu Marsudi Waras

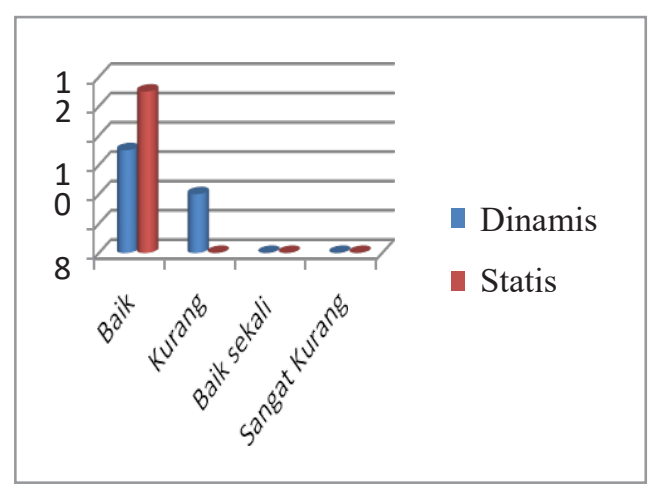

Diagram 1.3 Test Keseimbangan Posyandu Melati Arum 


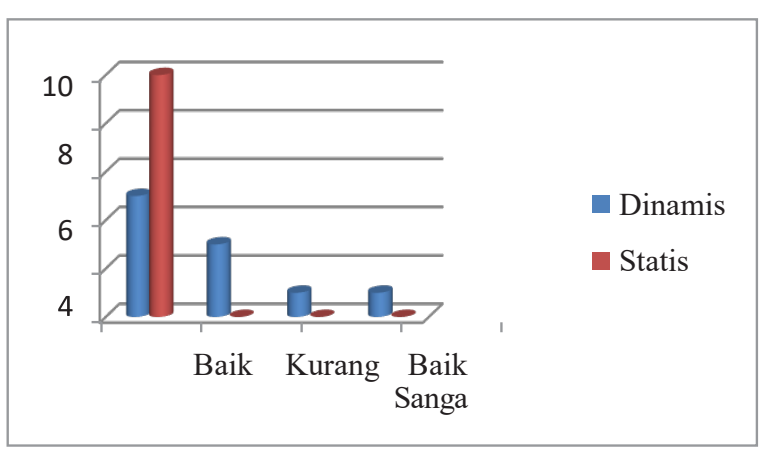

Diagram 1.4 Test Keseimbangan Posyandu Marsudi Waras

Tabel 1.1 Indeks Pemeriksaan Sikap Tubuh/ Koreksi Postur di Posyandu Melati arum

\begin{tabular}{ccc}
\hline Skor & Frekuensi & Persentase (\%) \\
\hline 90 & 1 & 8.33 \\
95 & 1 & 8.33 \\
100 & 3 & 25 \\
105 & 1 & 8.33 \\
110 & 6 & 50 \\
\hline Total & $\mathbf{1 2}$ & $\mathbf{1 0 0}$ \\
\hline
\end{tabular}

Tabel 1.2 Indeks Pemeriksaan Sikap Tubuh/ Koreksi Postur di Posyandu Marsudi Waras

\begin{tabular}{ccc}
\hline Skor & Frekuensi & Persentase (\%) \\
\hline 90 & 0 & 0 \\
95 & 2 & 18.18 \\
100 & 3 & 27.27 \\
105 & 0 & 0 \\
110 & 5 & 45.45 \\
\hline Total & $\mathbf{1 1}$ & $\mathbf{1 0 0}$ \\
\hline
\end{tabular}

Pada saat dilakukan penyuluhan di Posyandu wilayah Kentingan Jebres Surakarta yaitu di Posyandu Melati Arum dan Posyandu
Marsudi Waras sebelum di beri penyuluhan tentang deteksi dini resiko jatuh rata-rata pengetahuan lansia kurang paham sedangkan setelah di berikan penyuluhan tentang deteksi dini resiko jatuh pada lansia nilai rata-rata pengetahuannya menjadi tambah paham.

Berdasarkan beberapa penelitian menyatakan bahwa pendidikan kesehatan merupakan aktifitas pembelajaran yang dirancang oleh perawat sesuai kebutuhan klien. Pencapaian tujuan pendidikan kesehatan akan lebih mudah dengan penggunaan media pembelajaran yang sesuai dan dapat meningkatkan kemudahan penerimaan informasi. Menurut Nies dan McEwen (2001) dalam Mardhiah A, dkk. (2015) penggunaan alat bantu berupa tulisan akan lebih menghasilkan peningkatan pengetahuan daripada dengan kata-kata. Dengan demikian, setelah diberikan pendidikan kesehatan pengetahuan lansia bertambah yang awalnya belum tahu menjadi tahu. Menurut (Gejir \& Ratih, 2017) dalam (Iswati, Sulistyana CS. 2019) mengatakan bahwa upaya intervensi terhadap faktor perilaku dapat dilakukan melalui dua pendekatan, yaitu pendidikan atau paksaan/tekanan, dan pendekatan pendidikan merupakan yang paling tepat sebagai upaya untuk memecahkan masalah kesehatan masyarakat melalui faktor perilaku. Sementara itu penyuluhan kesehatan diartikan 
sebagai kegiatan pendidikan kesehatan yang dilakukan dengan cara menyebarluaskan pesan dan menanamkan keyakinan pada seseorang yang diberikan tambahan ilmu pengetahuan.

Lansia dengan diberikan pendidikan kesehatan akan lebih mengetahui tentang deteksi resiko jatuh pada lansia. Lansia sendiri akan mengalami berbagai perubahan pada diri lansia. Jatuh merupakan hal yang sering terjadi pada lansia karena beberapa kondisi dan faktor yang dapat mempengaruhinya. Jatuh bisa dicegah sedini mungkin pada lansia. Faktor keseimbangan juga bisa mempengaruhi.

Berdasarkan hasil pelatihan tentang keseimbangan lansia di Posyandu Lansia Melati Arum rata-rata test keseimbangan baik yaitu keseimbangan dinamis dan statis lebih dari 5. Posyandu lansia Marsudi Waras juga setelah diberikan latihan keseimbangan menunjukkan test keseimbangan dinamis dan statis baik. Dengan demikian resiko untuk jatuh kemungkinan besar kecil terjadi. Lansia yang jatuh akan mengakibatkan berbagai hal yang dapat mempengaruhi lansia itu sendiri.

Berdasarkan penelitian yang sudah dilakukan terkait tentang deteksi dini resiko jatuh pada lansia diantaranya penelitian oleh (Stanley \& Beare, 2012) dalam Fristantia,
2017 jatuh dapat mengakibatkan komplikasi dari yang paling ringan berupa memar dan keseleo sampai dengan patah tulang bahkan kematian. Oleh karena itu, harus dicegah agar jatuh tidak berulang-ulang dengan cara identifikasi faktor risiko, penilaian keseimbangan dan gaya berjalan, serta mengatur/mengatasi faktor situasional yang ada di lingkungannya.

Indeks Pemeriksaan Sikap Tubuh/ Koreksi Postur di Posyandu Melati Arum dan Marsudi Waras menunjukkan hasil yang bagus dengan nilai angka diatas 100. Menurut Mauk (2010) dalam (Fristantia, 2017) lansia juga sering mengalami kehilangan persepsi dan sensori terkait informasi yang mengatur pergerakkan tubuh dan posisi lansia serta hilangnya fiber sensori, reseptor vibrasi dan sentuhan dari ekstremitas bawah lansia yang menyebabkan berkurangnya kemampuan untuk memperbaiki pergerakkan sendi pada lansia yang pada akhirnya dapat mengakibatkan ketidakseimbangan tubuh sehingga lansia dapat terjatuh karena faktor tersebut.

Hasil penelitian dari Buatois et al. (2008) dalam Azizah, FD (2017) mengatakan bahwa aktivitas fisik secara teratur dapat meningkatkan input somatosensori dan penggunaan vestibular dan meningkatkan 


\section{GEMASSIKA: Jurnal Pengabdian Kepada Masyarakat}

Vol. 4 No. 2 November 2020

proses pusat integratif pada otak dengan melibatkan adaptasi yang cepat, serta menghasilkan motor strategi yang tepat untuk menjaga keseimbangan tubuh. Hal ini sesuai dengan penelitian Sutomo (2011) dalam Fristantia (2017) yang menyatakan bahwa ada hubungan antara gangguan saraf terhadap risiko jatuh pada lansia.

Penurunan keseimbangan pada seseorang bukan hanya sebagai akibat menurunnya kekuatan otot atau akibat penyakit yang diderita, melainkan juga keseimbangan dianggap sebagai penampilan yang tergantung atas aktivitas yang terus menerus dilakukan. Usia lanjut dalam kategori mandiri dapat diartikan juga usia lanjut yang mampu melakukan aktivitas sehari-hari secara mandiri tanpa tergantung kepada orang lain. Menurut Ruwer dalam Deniro, AJN, dkk. 2017 usia lanjut yang mandiri dalam aktivitas sehari-hari akan menurunkan kekakuan dan keketatan otot yang berpengaruh pada keseimbangan, kekuatan, dan kelenturan otot yang lebih baik dibandingkan usia lanjut dengan kategori tergantung atau dependen kepada orang lain. Hal ini yang berpengaruh pada penurunan risiko jatuh pada usia lanjut dengan kategori yang semakin mandiri dalam aktivitas sehari-hari.

Aktivitas sehari-hari dari lansia dengan penggunaan alat bantu berjalan dapat membantu meningkatkan keseimbangan, tetapi disisi lain dapat menyebabkan langkah yang terputus dan kecenderungan tubuh untuk membungkuk, terlebih jika alat bantu tidak menggunakan roda, karena itu penggunaan alat bantu berjalan harus disarankan secara individual. Apabila pada lansia terjadi kasus gangguan berjalan dan tidak dapat ditangani dengan obat- obatan atau pembedahan, maka salah satu penanganannya adalah dengan alat bantu berjalan seperti cane (tongkat), crutch (tongkat ketiak), dan walker. Pada saat kita memilih alat bantu untuk berjalan, anatomi tubuh dan sudut siku harus diperhatikan agar tidak terjadi resiko jatuh pada lansia (Darmojo, 2004 dalam Ramlis, R, 2018).

\section{KESIMPULAN}

Lansia mengetahui tentang cara deteksi dini resiko jatuh pada lansia mengetahui bagaimana apabila lansia mengalami jatuh dan bisa melakukan latihan-latihan untuk mendeteksi resiko jatuh pada lansia.

\section{SARAN}

Bagi lansia untuk lebih memperhatikan supaya tidak mudah untuk mengalami bisa jatuh. Lansia aktif melakukan latihan cara mendeteksi resiko jatuh pada lansia. 


\section{DAFTAR PUSTAKA}

Ashar, P.H. 2016. Gambaran Persepsi Faktor Resiko Jatuh pada Lansia di Panti Wredha Bumi Mulia 4 Margaguna. Jakarta Selatan. Skripsi. 2016. Universitas Islam Negeri Syarif Hidayatullah.

Azizah, FD. 2017. Hubungan Antara Aktivitas Fisik Dengan Resiko Jatuh Pada Lanjut Usia Di Desa Jaten Kecamatan Juwiring Klaten. Skripsi. Universitas Muhammadiyah Surakarta.

Condrowati. 2015. Analisis Pola Jalan Lanjut usia terhadap Risiko Jatuh di Posyandu Lansia Wilayah Surakarta. Naskah Publikasi. Universitas Muhammadiyah Surakarta.

Deniro, AJN, Sulistiyawati NN, Widajanti N. 2017. Hubungan Antara Usia Dan Aktivitas Sehari-Hari Dengan Risiko Jatuh Pasien Instalasi Rawat Jalan Geriatri. Jurnal Penyakit Dalam Indonesia. Vol.04 No.04 Desember 2017.

Fatimah. 2010. Merawat Manusia Lanjut Usia Suatu Pendekatan proses keperawatan gerontik. CV. Trans Info Media: JakartaAzizah, F.D, 2017. Hubungan Antara Aktivitas Fisik Dengan Resiko Jatuh Pada Lanjut Usia Di Desa Jaten Kecamatan Juwiring Klaten. Skripsi. Universitas Muhammadiyah Surakarta.

Fristantia, D.A, Zulfitri R, Hasneli Y. 2017. Analisis Faktor-faktor yang berhubungan dengan Risiko Jatuh pada Lansia yang tinggal di Rumah. Universitas Riau.

Iswati, Sulistyana CS. 2019. Peningkatan Pengetahuan Lansia tentang Pencegahan Jatuh melalui Penyuluhan di Asrama Brimob rt 02 rw 02 Kelurahan Morokrembangan kecamatan Krembangan Surabaya. Adi Husada Nursing Jurnal Vol 5 No 1 Juni 2019. Akademi Keperawatan Adi Husada Surabaya.

Kementrian kesehatan RI. 2014. Infodatin : Pusat Data dan Informasi kementrian kesehatan RI. 2014. Situasi dan analisi lanjut usia. diakses tgl 17 Januari 2020 dari http://www. pusdatin.kemkes.go.id/resources/download/pusdatin/infodatin/info datin-lansia.pdf 
GEMASSIKA: Jurnal Pengabdian Kepada Masyarakat

Vol. 4 No. 2 November 2020

Mardhiah A, Abdullah A, Hermansyah. 2015. Pendidikan Kesehatan Dalam Peningkatan Pengetahuan, Sikap Dan Keterampilan Keluarga Dengan Hipertensi - Pilot Study Jurnal Ilmu Keperawatan ISSN: 2338-6371

Ramlis, R. 2018. Faktor-faktor yang Berhubungan dengan Resiko Jatuh pada Lansia di BPPLU Kota Bengkulu tahun 2017. JNPH. Volume 6 No. 1 (April 2018). 